\title{
Formulation and Evaluation of Oral Controlled Release Osmotic Tablets of Glimepiride
}

\author{
P. Sandhya ${ }^{1,2}$, Hafsa Siddiqua $^{1}$, Ayesha sultana ${ }^{1}$, M. Sunitha ${ }^{1}$, R.Sunil $^{3}$. \\ ${ }^{1}$ Shadan Womens College of Pharmacy, Khairatabad, Hyderabad. \\ ${ }^{2}$ University College of Technology, Osmania University, Hyderabad, India. \\ ${ }^{3}$ St.Peters College of Pharmacy, Madikonda, Hanumakonda.
}

\begin{abstract}
Glimepiride has a relatively short elimination half-life (5 h), thereby requiring twice or thrice daily dosing in patients, which may lead to non-compliance. Controlled release formulations of Glimepiride were developed based on osmotic technology. Formulation F9 was selected as optimized formulation. The effect of different formulation variable was studied to optimize release profile. The release rate increased significantly as the increase of osmogen ratio from 1:0.5 to 1:1. The release rate increased significantly with the increase of concentration of pore forming agent (PEG-400) as noticed from the dissolution profile of the formulations. Thus drug release was inversely proportional to the concentration of osmogen in the core and the amount of pore forming agents in the coated tablets. The drug release from developed formulations was independent of $\mathrm{pH}$. The manufacturing procedure was standardized and found to be reproducible. Further studies are needed to investigate this formulation for its performance in vivo.
\end{abstract}

Keywords: controlled release, osmogen, osmotic technology, pore forming agent.

\section{INTRODUCTION}

The oral route for drug delivery is the most popular, desirable, and most preferred method for administrating therapeutically agents for systemic effects because it is a natural, convenient, and cost effective to manufacturing process. Oral route is the most commonly used route for drug administration. Although different route of administration are used for the delivery of drugs, oral route remain the preferred mode. Even for sustained release systems the oral route of administration has been investigated the most because of flexibility in designing dosage forms.

Present controlled release drug delivery systems are for a maximum of 12 hours clinical effectiveness. Such systems are primarily used for the drugs with short elimination half life.

\section{Oral controlled release dosage form}

The treatment of acute diseases or chronic illnesses has been achieved by delivery of drugs to the patients for many years. These drug delivery systems include tablets, injectables, suspensions, creams, ointments, liquids, and aerosols. Today these conventional drug delivery systems are widely used. The term drug delivery can be defined as techniques that are used to get the therapeutic agents inside the human body ${ }^{1}$.

Conventional drug therapy require periodic doses of therapeutic agents. These agents are formulated to produce maximum stability, activity and bioavailability. For most drugs, conventional methods of drug administration are effective, but some drugs are unstable or toxic and have narrow therapeutic ranges. Some drugs also possess solubility problems.

\section{Lee et al ${ }^{17}$}

\section{Review of Literature}

Developed the monolithic osmotic tablet system, which is composed of a monolithic tablet coated with cellulose acetate (CA) membrane drilled with two orifices on both side surfaces, has been described. The influences of tablet formulation variables including molecular weight (MW) and amount of polyethylene oxide (PEO), amount of potassium chloride ( $\mathrm{KCl})$, and amount of rice starch as well as nifedipine loading have been investigated. Orifice size and membrane variables including nature and amount of plasticizers as well as thickness on drug release have also been studied. It was found that PEO with MW of $300000 \mathrm{~g} / \mathrm{mol}$ was suitable to be thickening agent, both amount of $\mathrm{KCl}$ and amount of PEO had comparable and profoundly positive effects, while nifedipine loading had a strikingly negative influence on drug release.

\section{Ritesh B. Patel et al ${ }^{18}$}

Developed osmotic pump tablets (OPT) of Glimepiride (GLZ) and optimized the formulation using response surface methodology. The complex of GLZ and HP- $\beta$-CD were prepared and studied the effects of 
different ratio of drug to HP- $\beta-C D$ and preparation methods on complex formation. The release from the optimized formulations was independent of $\mathrm{pH}$ and agitation intensity of the release media, assuring the release to be fairly independent of $\mathrm{pH}$ and hydrodynamic conditions of the body. The drug release from optimized formulation showed a controlled release pattern.

\section{Vavia et al ${ }^{19}$}

Studied a controlled porosity osmotic pump-based drug delivery system., pseudoephedrine was chosen as a model drug with an aim to develop a controlled release system for a period of $12 \mathrm{~h}$. Sodium bicarbonate was used as the osmogent. The effect of different ratios of drug:osmogent on the in-vitro release was studied. Cellulose acetate (CA) was used as the semipermeable membrane.

\section{Preformulation studies}

\section{Materials \& Methods}

Preformulation testing is the first step in the rationale development of dosage forms of a drug. It can be defined as an investigation of physical and chemical properties of drug substance alone and when it combined with excipients.

\section{FTIR spectrum interpretation}

The infrared spectrum of the pure Glimepiride sample was recorded and the spectral analysis was done. The dry sample of drug was directly placed after mixing and triturating with dry potassium bromide. The pure drug and polymers were subjected to FTIR studies alone and in combination, to study the interference of polymer for drug analysis.

\section{Determination of $\lambda$ max}

A 10mg of Glimepiride sample was accurately weighed and was first dissolved in $5 \mathrm{ml}$ methanol and volume was made upto $10 \mathrm{ml}$ with $0.1 \mathrm{~N} \mathrm{Hcl}$ solution. From the standard stock solution, $1 \mathrm{ml}$ was diluted to 10 $\mathrm{ml}$ with $0.1 \mathrm{~N} \mathrm{Hcl} \mathrm{solution.} \mathrm{The} \mathrm{resulting} \mathrm{solution} \mathrm{containing} 10 \mathrm{mcg} / \mathrm{ml}$ was scanned between 200 to $400 \mathrm{~nm}$. Similar procedure was carried out for $\mathrm{pH} 6.8$ buffer solution and $\mathrm{pH} 7.4$ buffer solution, absorbance was measured at $230 \mathrm{~nm}$.

\section{Preparation of osmotic tablets of Glimepiride}

All the ingredients were blended thoroughly and directly compressed on tablet punching machine.

\section{Evaluation of prepared tablets}

The prepared tablets were evaluated for weight variation, hardness, friability, disintegration time and percentage drug release.

\section{FIGURES AND TABLES}

\begin{tabular}{|l|l|l|l|l|l|l|l|l|l|l|l|l|}
\hline S.No & \multicolumn{1}{|c|}{ Ingredient (mg) } & \multicolumn{9}{|c|}{ Core Tablet } \\
\cline { 3 - 13 } & & F1 & F2 & F3 & F4 & F5 & F6 & F7 & F8 & F9 & F10 \\
\hline 1 & Glimepiride & 8 & 8 & 8 & 8 & 8 & 8 & 8 & 8 & 8 & 8 \\
\hline 2 & Mannitol & 4 & 4 & 4 & 4 & 4 & 4 & 8 & 8 & 8 & 8 \\
\hline 3 & PVP & 15 & 15 & 15 & 15 & 15 & 15 & 15 & 15 & 15 & 15 \\
\hline 4 & MCC & 120 & 120 & 120 & 120 & 120 & 120 & 116 & 116 & 116 & 116 \\
\hline 5 & Aerosil & 1.5 & 1.5 & 1.5 & 1.5 & 1.5 & 1.5 & 1.5 & 1.5 & 1.5 & 1.5 \\
\hline 6 & Magnesium stearate & 1.5 & 1.5 & 1.5 & 1.5 & 1.5 & 1.5 & 1.5 & 1.5 & 1.5 & 1.5 \\
& & & & & & & & & & & \\
\hline 7 & CAP & $3 \%$ & $3 \%$ & $3 \%$ & $3 \%$ & $3 \%$ & $3 \%$ & $3 \%$ & $3 \%$ & $3 \%$ & $3 \%$ \\
\hline 8 & Dibutyl phthalate(v/w) & $15 \%$ & $15 \%$ & $15 \%$ & $15 \%$ & $15 \%$ & $15 \%$ & $15 \%$ & $15 \%$ & $15 \%$ & $15 \%$ \\
\hline 9 & PEG-400 & $5 \%$ & $5 \%$ & $5 \%$ & $10 \%$ & $10 \%$ & $10 \%$ & $5 \%$ & $5 \%$ & $5 \%$ & $10 \%$ \\
\hline & Weight gain (\%) & 2.5 & 5 & 10 & 2.5 & 5 & 10 & 2.5 & 5 & 10 & 2.5 \\
\hline
\end{tabular}

Table 1: Formulation chart of osmotic tablets of Glimepiride 


\begin{tabular}{|l||c|c|c|c|c||}
\hline \multicolumn{1}{|c|}{ Drug/ Polymer } & N-H Stretch & C-H Aromatic & C=O Amide & $\begin{array}{c}\text { Methylene } \\
\text { Cyclohexane }\end{array}$ & Sulfoxides \\
\hline \hline Glimepiride & 3369.13 & 2930.39 & 1707.64 & 1673.89 & 1079.85 \\
\hline \hline $\begin{array}{l}\text { Glimepiride+ } \\
\text { Mannitol }\end{array}$ & 3414.86 & 2850.02 & 1729.18 & 1620.46 & 1074.46 \\
\hline \hline $\begin{array}{l}\text { Glimepiride+ } \\
\text { MCC }\end{array}$ & 3393.63 & 2917.75 & 1699.96 & 1657.13 & 1028.76 \\
\hline \hline $\begin{array}{l}\text { Glimepiride } \\
\text { osmotic tablet }\end{array}$ & 3410.10 & 2977.25 & 1704.35 & 1671.90 & 1072.41 \\
\hline \hline
\end{tabular}

Table 2: IR spectral peaks for Glimepiride and Superdisintegrants *All values expressed in $\mathrm{cm}^{-1}$ FTIR Spectral data

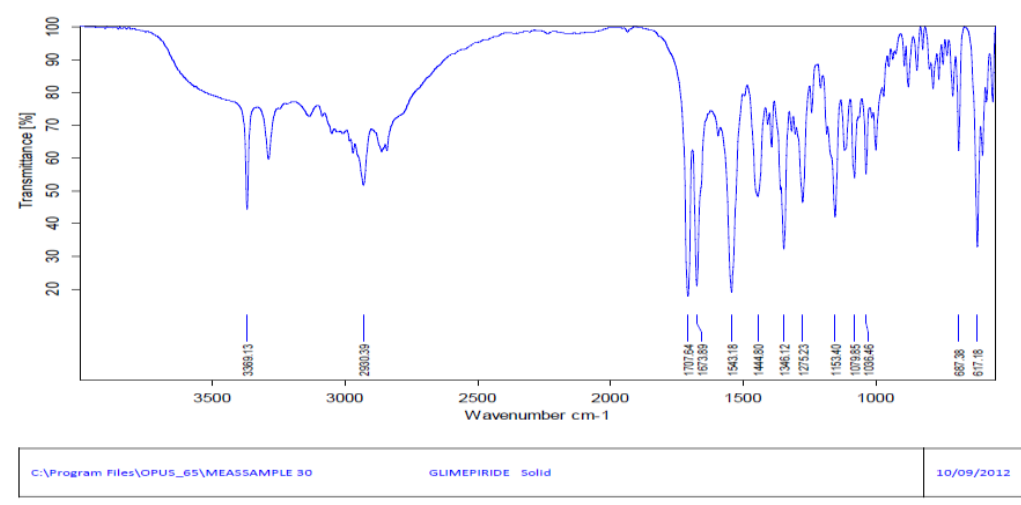

Fig 1: FTIR Spectra of Glimepiride solid
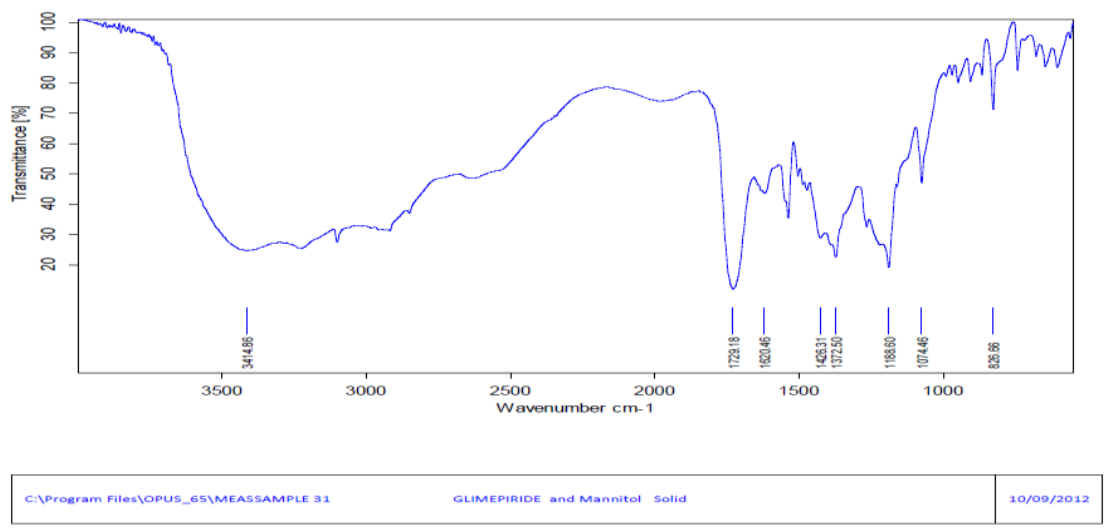

Fig 2: FTIR Spectra of Glimepiride and Mannitol solid

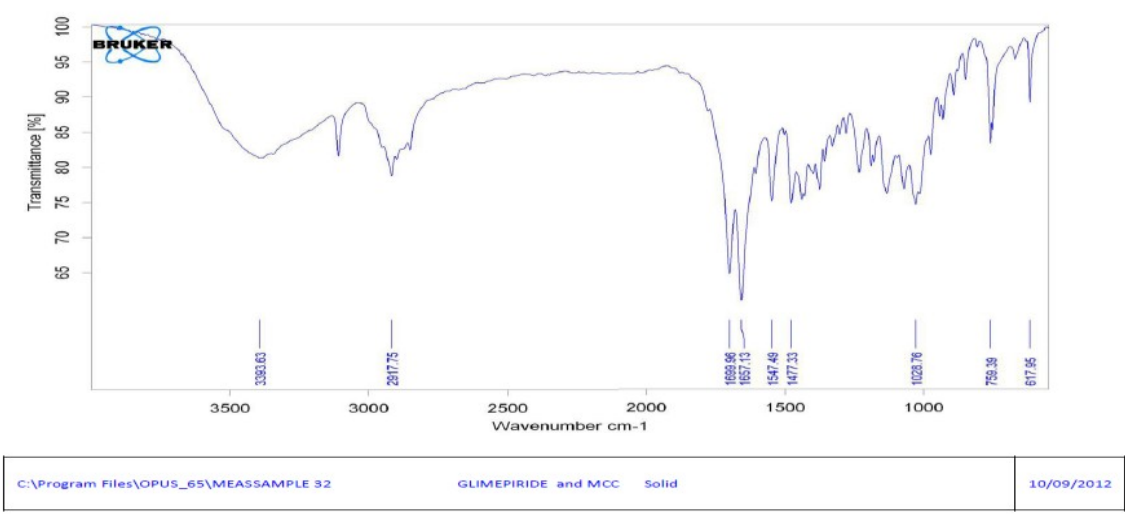

Fig 3: FTIR Spectra of Glimepiride and MCC solid 


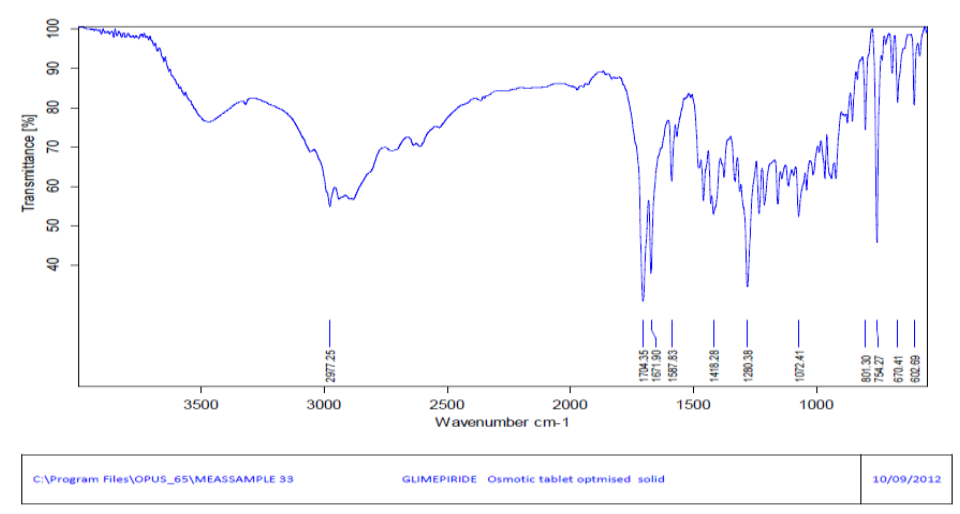

Fig 4: FTIR Spectra of Glimepiride optimized osmotic tablet solid

Table 3: Post compression parameters of Glimepiride osmotic tablets

\begin{tabular}{|c|c|c|c|c|c|c|}
\hline S.No & Formulation & $\begin{array}{c}\text { Weight } \\
\text { variation }(\mathrm{mg})\end{array}$ & $\begin{array}{c}\text { Hardness } \\
\left(\mathrm{kg} / \mathrm{cm}^{2}\right)\end{array}$ & $\begin{array}{c}\text { Thickness } \\
(\mathrm{mm})\end{array}$ & $\begin{array}{c}\text { Friability } \\
(\%)\end{array}$ & Assay $(\%)$ \\
\hline 1 & F1 & 151 & 3.33 & 1.59 & 0.43 & 97.23 \\
\hline 2 & F2 & 147 & 3.66 & 1.64 & 0.34 & 98.55 \\
\hline 3 & F3 & 148.5 & 3.66 & 1.59 & 0.49 & 98.16 \\
\hline 4 & F4 & 149 & 4.00 & 1.58 & 0.47 & 99.34 \\
\hline 5 & F5 & 148.5 & 3.66 & 1.59 & 0.49 & 98.16 \\
\hline 6 & F6 & 147 & 3.66 & 1.64 & 0.34 & 98.55 \\
\hline 7 & F7 & 148.5 & 3.66 & 1.59 & 0.49 & 98.16 \\
\hline 8 & F8 & 152.5 & 3.66 & 1.56 & 0.34 & 99.25 \\
\hline 9 & F9 & 152.5 & 3.66 & 1.56 & 0.34 & 99.25 \\
\hline 10 & F10 & 149 & 4.00 & 1.58 & 0.47 & 99.34 \\
\hline
\end{tabular}

Table 4: Dissolution data of Glimepiride osmotic tablets

\begin{tabular}{|c|c|c|c|c|c|c|c|c|c|c|}
\hline S.No & $\begin{array}{l}\text { Formul } \\
\text { ation }\end{array}$ & $\begin{array}{l}0 \\
\min \end{array}$ & $1 \mathrm{hr}$ & $2 \mathrm{hr}$ & $3 \mathrm{hr}$ & $4 \mathrm{hr}$ & $5 \mathrm{hr}$ & $6 \mathrm{hr}$ & $8 \mathrm{hr}$ & $12 \mathrm{hr}$ \\
\hline 1 & F1 & 0 & 8.98 & 18.68 & 22.5 & 26.71 & 28.06 & 30.21 & 46.07 & 61.04 \\
\hline 2 & F2 & 0 & 10.51 & 21.39 & 26.02 & 31.32 & 33.5 & 45.09 & 56.08 & 72.06 \\
\hline 3 & F3 & 0 & 11.62 & 23.54 & 28.72 & 35.66 & 38.33 & 42.6 & 63.48 & 81.51 \\
\hline 4 & $\mathrm{~F} 4$ & 0 & 9.85 & 21.09 & 27.75 & 31.62 & 34.72 & 40.25 & 54.93 & 76.73 \\
\hline 5 & F5 & 0 & 12.63 & 25.08 & 29.72 & 38.44 & 42.26 & 45.52 & 65.46 & 83.76 \\
\hline 6 & F6 & 0 & 14.46 & 30.87 & 36.54 & 48.32 & 52.31 & 56.72 & 69.53 & 76.58 \\
\hline 7 & F7 & 0 & 12.03 & 26.31 & 30.52 & 42.74 & 48.78 & 52.23 & 67.32 & 84.66 \\
\hline 8 & F8 & 0 & 14.69 & 36.37 & 42.35 & 51.79 & 55.74 & 60.1 & 77.44 & 88.25 \\
\hline 9 & F9 & 0 & 17.2 & 39.42 & 44.52 & 53.68 & 57.34 & 61.23 & 80.69 & 99.87 \\
\hline 10 & F10 & 0 & 21.39 & 30.87 & 36.54 & 42.74 & 56.72 & 69.53 & 97.63 & - \\
\hline
\end{tabular}

Table 5: Release kinetics of Glimepiride osmotic tablets

\begin{tabular}{|l|l|l|l|l|l|l|l|l|l|l|}
\hline S.No & Formulation & \multicolumn{2}{l|}{ Korse Meyer Peppas } & \multicolumn{2}{l|}{ Zero Order } & \multicolumn{2}{l|}{ First Order } & \multicolumn{2}{l|}{ Higuchi } \\
\hline & & N & Kkp & R2 & K0 & R2 & K & R2 & KH & R2 \\
\hline 1 & F1 & 0.719 & 0.987 & 0.969 & 4.809 & 0.969 & -0.032 & 0.973 & 17.26 & 0.937 \\
\hline 2 & F2 & 0.755 & 1.049 & 0.985 & 5.878 & 0.973 & -0.045 & 0.987 & 21.25 & 0.954 \\
\hline 3 & F3 & 0.758 & 1.089 & 0.982 & 6.709 & 0.979 & -0.061 & 0.950 & 23.97 & 0.937 \\
\hline 4 & F4 & 0.777 & 1.033 & 0.982 & 6.098 & 0.983 & -0.049 & 0.963 & 21.78 & 0.941 \\
\hline 5 & F5 & 0.747 & 1.122 & 0.986 & 7.010 & 0.980 & -0.071 & 0.937 & 25.14 & 0.945 \\
\hline 6 & F6 & 0.721 & 1.213 & 0.980 & 7.571 & 0.961 & -0.109 & 0.870 & 27.79 & 0.971 \\
\hline 7 & F7 & 0.788 & 1.124 & 0.985 & 7.397 & 0.975 & -0.083 & 0.930 & 26.78 & 0.959 \\
\hline 8 & F8 & 0.712 & 1.254 & 0.954 & 7.818 & 0.940 & -0.155 & 0.820 & 29.09 & 0.977 \\
\hline 9 & F9 & 0.656 & 1.310 & 0.956 & 7.790 & 0.928 & -0.207 & 0.767 & 29.23 & 0.980 \\
\hline 10 & F10 & 0.703 & 1.279 & 0.944 & 11.17 & 0.977 & -0.165 & 0.726 & 31.75 & 0.899 \\
\hline
\end{tabular}




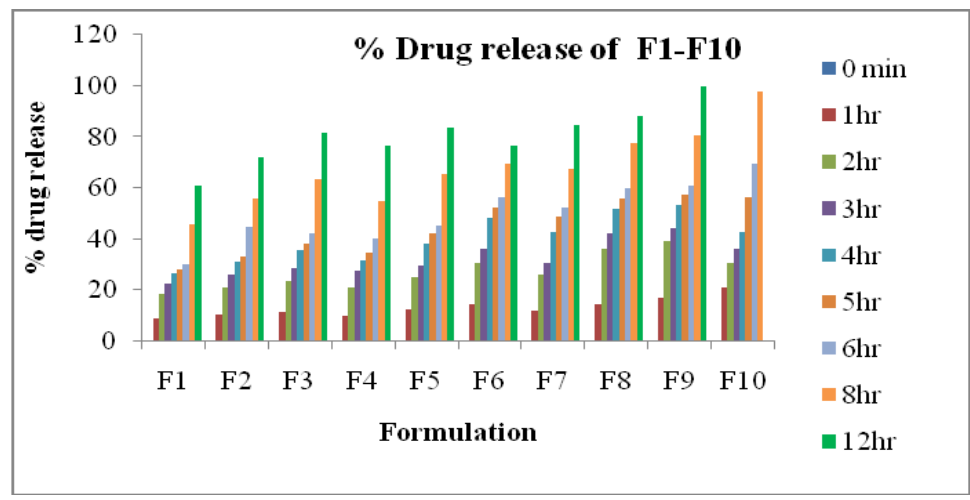

Fig.5: Dissolution profile of Glimepiride osmotic tablets F1-F10

\section{DISCUSSION}

\section{Standard Calibration Curve of Glimepiride}

It was found that the estimation of Glimepiride by UV spectrophotometric method at $\lambda_{\max } 230.0 \mathrm{~nm}$ in $0.1 \mathrm{~N}$ Hydrochloric acid, $\lambda_{\max } 228.0 \mathrm{~nm}$ in $6.8 \mathrm{pH}$ buffer, $\lambda_{\max } 228.0 \mathrm{~nm}$ in $7.4 \mathrm{pH}$ buffer all of them had good reproducibility and this method was used in the study. The correlation coefficient for the standard curve was found to be closer to 1 in all the media.

\section{Fourier Transform Infrared spectroscopy}

The present study was carried out to develop osmotic tablets of Glimepiride by direct compression of core tablets followed by spray coating with polymers and pore formimg agent. Hence it was necessary to find suitable excipients with good compatibility.

The IR spectrum of Glimepiride is shown in Table 2, Fig 1, reveals characteristic shoulders in the Glimepiride IR spectrum that occur These bands were also observed for the physical mixture of excipients and Glimepiride with the same absorbance as shown in Fig 2, 3, 4. From these results, it can be confirmed that there is no interaction between Glimepiride and excipients in the physical mixture.

\section{Tablet formulation}

\section{Formulation of Glimepiride Osmotic Tablets by Direct Compression}

The present study of Glimepiride by direct compression method reveals that the flow properties of the powder blend is showing the good flow property. (Table 1)

\section{Evaluation Parameters for osmotic Tablets of Glimepiride Weight variation test}

Tablets of each batch were subjected to weight variation test, difference in weight and percent deviation was calculated for each tablet and was shown in the Table 3. The average weight of the tablet is approximately in range 147 to 152.5 , so the permissible limit is $\pm 10 \%$ (135-165mg). The results of the test showed that, the tablet weights were within the pharmacopoeia limit.

\section{Hardness test}

Hardness of the three tablets of each batch was checked by using monsanto hardness tester and the data's were shown in Table 3. The results showed that the hardness of the tablets is in range of 3.00 to 4.00 $\mathrm{kg} / \mathrm{cm}^{2}$, which was within IP limits.

\section{Thickness}

Thickness of three tablets of each batch was checked by using Vernier Caliper and data shown in Table 3. The result showed that thickness of the tablet is raging from 2.16 to $2.75 \mathrm{~mm}$.

\section{Friability}

Tablets of each batch were evaluated for percentage friability and the data's were shown in the Table 3. The average friability of all the formulations lies in the range of 0.34 to $0.43 \%$ which was less than $1 \%$ as per official requirement of IP indicating a good mechanical resistance of tablets. 


\section{In vitro dissolution studies}

Finally, the tablets were evaluated for in vitro dissolution studies in acid buffer (pH-1.2) for 2 hours followed by $\mathrm{pH} 6.8$ buffers for 3 hours and finally for $7 \mathrm{hrs}$ in $\mathrm{pH} 7.4 \mathrm{pH}$ buffer. The results were shown in the Table 4. Formulations F1- F5 could not release maximum amount of drug from formulations till $12 \mathrm{hrs}$ of dissolution study. Formulations F6-F9 showed a sustained drug release till 12 hours of dissolution study of which Formulation F9 has showed maximum amount of drug released with drug release of $9.87 \%$ at the end of $12^{\text {th }}$ hour, so it is choosen as an optimized formulation. On the other end formulations F10-F12 complete release of drug within 8 hours of dissolution study. The reason may be due to increase in concentration of pore forming agent $(10 \%)$. The results are shown in Fig 5.

Assay

The percentage drug content of all the tablets was found to be between $97.23 \pm 0.280 \%$ and $99.25 \pm 0.670 \%$ of Glimepiride, which was within the acceptable limits. This result indicates that there was uniform distribution of the drug throughout the batch.

\section{CONCLUSION}

Glimepiride has a relatively short elimination half-life $(5 \mathrm{~h})$, thereby requiring twice or thrice daily dosing in patients, which may lead to non-compliance. Controlled release formulations of Glimepiride were developed based on osmotic technology. Formulations F1- F5 could not release maximum amount of drug from formulations till $12 \mathrm{hrs}$ of dissolution study. Formulations F6-F9 showed a sustained drug release till 12 hours of dissolution study of which Formulation F9 has showed maximum amount of drug released with drug release of $9.87 \%$ at the end of $12^{\text {th }}$ hour, so it is choosen as an optimized formulation. The effect of different formulation variable was studied to optimize release profile. The release rate increased significantly as the increase of osmogen ratio from 1:0.5 to 1:1. The release rate increased significantly with the increase of concentration of pore forming agent (PEG-400) as noticed from the dissolution profie of the formulations. Thus Drug release was inversely proportional to the concentration of osmogen in the core and the amount of pore forming agents in the coated tablets. The release from developed formulations was independent of $\mathrm{pH}$. The manufacturing procedure was standardized and found to be reproducible. Further studies are needed to investigate this formulation for its performance in vivo.

\section{References}

[1]. T W Lee, J R Robinson, In Remington: The science and practice of pharmacy., Gennaro, Ed.; Lippincott Williams and Wilkins: Baltimore, 2nd edition. 2000: 903-929.

[2]. Nandita Das and Sudip Das, Controlled Release of Oral Dosage Forms Formulation., Fill \& Finish; 2003: 10-15.

[3]. H C Ansel, L V Allen, Jr. N C Popovich, Pharmaceutical dosage forms and drug delivery systems., Lippincott Williams and Wilkins; $\quad$ Baltimore 7 edition. 2000:23.

[4]. S.P.vyas, R.k.khar, "controlled drug delivery concepts and advances";osmotically regulated systems, first edition, 477-501.

[5]. Rajan K. Verma, Sanjay Garg, "Formulation aspects in the development of osmotically controlled oral drug delivery systems", Journal of Controlled Release 79 (2002) 7-27.

[6]. Welling P. G. and Dobrinska M. R., Dosing consideration and bioavailability assessment of controlled drug delivery system, Chapter.

[7]. Controlled drug delivery; fundamentals and applications, $2^{\text {nd }}$ edition, Robinson J.R. and Lee V. H. L. (Eds.), Marcel Dekker Inc., New York, 1978, 29,p. 254, 373.

[8]. Jain N.K., "Advances in Novel and Controlled Delivery", 18-39.

[9]. Gupta roop, Gupta rakesh,,Rathore Garvendra " Osmotically controlled drug delivery systems- A review" Int. J. Ph. Sci., SeptDecember 2009,Vol. 1 271, Issue 2 269-275.

[10]. Longxiao Liu, Gilson Khang, John M. Rhee, Hai Bang Lee, "Monolithic osmotic tablet system for nifedipine delivery", Journal of Controlled Release 67 (2000) 309-322.

[11]. Mathiowitz, E., (Eds); Encyclopedia Of Controlled Drug Delivery, Vol 1, Wiley Intrescience Publication, 1999, p.415.

[12]. Martin, Physical Pharmacy, $4^{\text {th }}$ edition, chapter-12, p-286.

[13]. C.V.S. Subramanyam, Text book of Physical Pharmaceutics, thoroughly revised and enlarge, chapter-1, p-24.

[14]. C.V.S. Subrahmanyam, Text book of Physical Pharmaceutics, thoroughly revised and enlarge, chapter-1, p-124.

[15]. Martin, Physical Pharmacy, $4^{\text {th }}$ edition, chapter-12, p-333.

[16]. Brahmankar D. M. and Jaishwal S. B., Biopharmaceutics and Pharmacokinetics A Trease, $1^{\text {st }}$ edition, Vallabh Prakashan, Delhi 1995, p.335.

[17]. Costa,P.,Lobo,J.M.S., "Modeling and composition of dissolution profile" Eur.J.Pharm Sci., 2001,13,123-133.

[18]. Longxiao Liu, Gilson Khang, John M. Rhee, Hai Bang Lee, "Monolithic osmotic tablet system for nifedipine delivery", Journal of Controlled Release 67 (2000) 309- 322.

[19]. Ritesh B. Patela, , H. R. Patel, G. N. Patel, R. P. Patel, M. M. Patel, Development of osmotically controlled drug delivery system by inclusion complex with HP- $\beta$-CD of glipizide: optimization of formulation using response surface methodology" Asian Journal of Pharmaceutical Sciences 2010, 5 (2): 74-86.

[20]. Sapna N. Makhija, Pradeep R. Vavia, "Controlled porosity osmotic pump-based controlled release systems of pseudoephedrine. Cellulose acetate as a semipermeable membrane", Journal of Controlled Release 89 (2003) 5-18.

[21]. Liu, J. Ku, G. Khang, B. Lee, J.M. Rhee, H.B. Lee, "Nifedipine controlled delivery by sandwiched osmotic tablet system", J. Control. Release 68 (2000) 145-156.

[22]. B Mishra, BK Makesh, C Sankar" Oral push-pull osmotic pumps of pentazocine hydrochloride: Development and evaluation" 
Indian Journal of Pharmaceutical Sciences Year : 2006 Volume : 68 Issue : 1,: 85-87.

[23]. Yan Zhang, Zhirong Zhang, Fang Wu, "A novel pulsed-release system based on swelling and osmotic pumping mechanism", Journal of Controlled Release Volume 89, Issue 1 , 14 April 2003, Pages 47-55.

[24]. D. Prabakaran, Paramjit Singh, Parijat Kanaujia, K.S. Jaganathan, Amit Rawat, Suresh P. Vyas, "Modified push-pull osmotic system for simultaneous delivery of theophylline and salbutamol: development and invitro characterization", International Journal of Pharmaceutics 284 (2004) 95-108

[25]. En-Xian Lu1, Zhi-Qiang Jiang, Qi-Zhi Zhang, Xin-Guo Jiang, "A water-insoluble drug monolithic osmotic tablet system utilizing gum arabic as an osmotic, suspending and expanding agent", Journal of Controlled Release 92 (2003) 375-382.

[26]. Xiao-dong Lia, Wei-san Pana,, Shu-fang Niea, Li-jun Wu, "Studies on controlled release effervescent osmotic pump tablets from Traditional Chinese Medicine Compound Recipe", Journal of Controlled Release 96 (2004) 359- 367. 